Proceedings of the 2005 Winter Simulation Conference

M. E. Kuhl, N. M. Steiger, F. B. Armstrong, and J. A. Joines, eds.

\title{
SIMULATION ANALYSIS OF INBOUND CALL CENTER OF A CITY-GAS COMPANY
}

\author{
Soemon Takakuwa \\ Graduate School of Economics and Business \\ Administration \\ Nagoya University \\ Furo-cho, Chikusa-ku, Nagoya, Aichi 464-8601, JAPAN
}

Takako Okada

\author{
Corporate Information System Company \\ Matsushita Electric Industrial Co., Ltd. \\ 1006 Kadoma, Kadoma City, Osaka 571-8501, JAPAN
}

\begin{abstract}
An inbound call center of a city-gas company was simulated to examine the proper target of the service level procedures were proposed to find the optimal number of agents, considering their skills and the scheduling of the agents to meet the frequency of customer calls. First, integer programming was adopted to obtain an initial feasible solution. Second, a special-purpose system was designed and developed to modify planned recesses for each agent. Then, optimal solutions were obtained by performing simulation together with direct-search methods. The proposed procedure was applied to a real case in order to confirm its effectiveness.
\end{abstract}

\section{INTRODUCTION}

Call-center managers wish to improve call-center performance, and need powerful decision-making tools to visualize, analyze, and enhance call-center business processes. The best tools available today to perform these functions are simulation tools (Anton, Bapat, and Hall 1999).

Several studies have focused on various issues concerned with call centers. For example, large call-center models were modeled and analyzed by Tanir and Booth (1999). Performance was measured within the call center at the service level, which was defined as the percentage of customers served within some fixed time period, known as the service level target. The issue of service level was treated based on the length of the processing time in research by Klunge (1999). Both inbound and outbound calls were treated and analyzed from the standpoint of the agents skill by Mehrotra and Fama (2003) and Pichitlamken et al. (2003). Henderson and Mason (1998) proposed that simulation modeling in conjunction with integer programming be used for staff allocations. Analysis on skillbased routing has been made for online routing of incoming calls (Koole et al. 2003; Mazzuchi and Wallace 2004). Furthermore, a manager-friendly platform for simulation modeling was introduced by utilizing Excel spreadsheet (Saltzman and Mehrotra 2004).
In this study, simulation tools were used for ad hoc problem analysis such as scheduling agents and skill analysis. First, the frequency of customer calls was carefully reviewed. The call arrival rate for this system varied over the course of the day. By using the constrained directsearch methods, which included a simulation and integer programming, the optimal solutions satisfying the designated service level were obtained.

\section{THE CALL CENTER OF A CITY-GAS COMPANY}

Toho Gas Co., Ltd. represents the third largest city-gas provider in Japan, and its service area encompasses three central prefectures in Japan: Aichi, Gifu, and Mie. In addition to the city gas and liquefied petroleum gas (LPG) business, the company is also engaged in complementary activities, such as engineering and business that foster comfortable living environments. According to the company website, its customer base exceeds 2.1 million, and the volume of gas sold has topped approximately 3 billion cubic meters in the business year 2004.

The company has currently nine service centers and thirteen business centers in its territory. The customer calls were once received at either a service center or a business center. Recently, the company has established one call center to receive customer calls transferred automatically from service centers or business centers. They have kept data on the number of calls over the course of the day, the week, and the season, for the past years. The company wishes to make their decisions especially based on the number of agents and working hours for skill-classified agents.

The overall layout of the call center is shown in Figure 1. In general, the business year and academic year begin in April and end in March in Japan. Therefore, many people change their places of residence to make new livings at the turn of the fiscal year. At this time, the number of calls to the call center reaches a peak throughout the year. 


\section{Takakuwa and Okada}

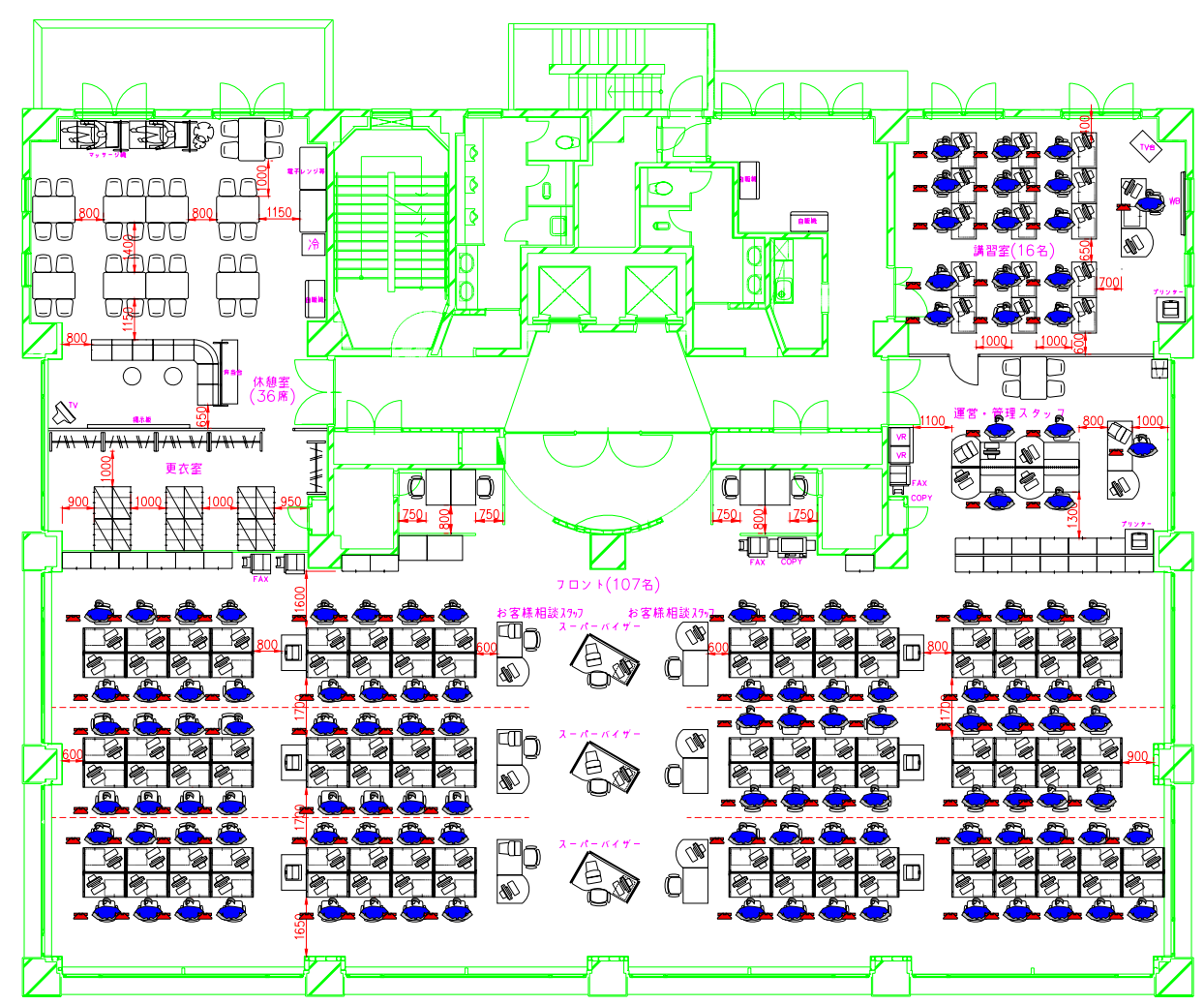

Figure 1: Overall Layout of the Call Center

The numbers of calls during the business hours are shown in Figure 2 as three typical seasons: the busiest, the normal, and the dull seasons. Agents receive inbound calls at the call center at 8:30 AM through 8:00 PM on weekdays, and the assignment of shift patterns to agents are set, as shown in Figure 3. In addition, agents are dispatched, and paid a salary calculated on the basis of each days of work and on the degree of their skill. The level of agent skill is classified into three categories: low, middle, and high degrees of operational performance. Once an agent finishes talking with a customer, after-call work is required by the same agent to process and record what the customer is inquiring about. Specific talk time and after-call work time are summarized in Table 1 for the three types of skill of the agents. In addition, the parameters of eligible agents such as labor time, breaks and wages are summarized in Table 2. These parameters are used to perform resource planning via integer linear programming for obtaining the initial feasible solution in seeking the optimal solutions.

The flow of calls is illustrated in Figure 4. One generic call center provides a central number in an organization that customers call. This central number feeds 92 trunk lines. If all 92 lines are in use, a caller gets a busy signal. The simulation models in this study were created using Arena (Kelton, Sadowski, and Sturrock 2004).

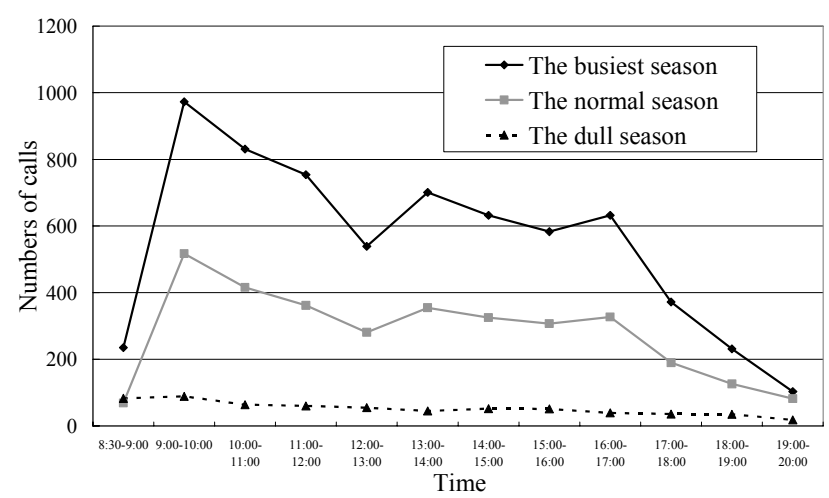

Figure 2: Number of Calls at Typical Seasons

\section{PROCEDURE TO SEEK THE OPTIMAL SOLUTION}

\subsection{The Procedures}

The objective in this study was to minimize the total daily personnel expenses, satisfying a certain service level target for the expected number of calls to the call center. A performance measure within the call center is the service level, which is defined as the percentage of customers served within some fixed time period, known as the service level target. For example, in cases where $95 \%$ of custom- 


\section{Takakuwa and Okada}

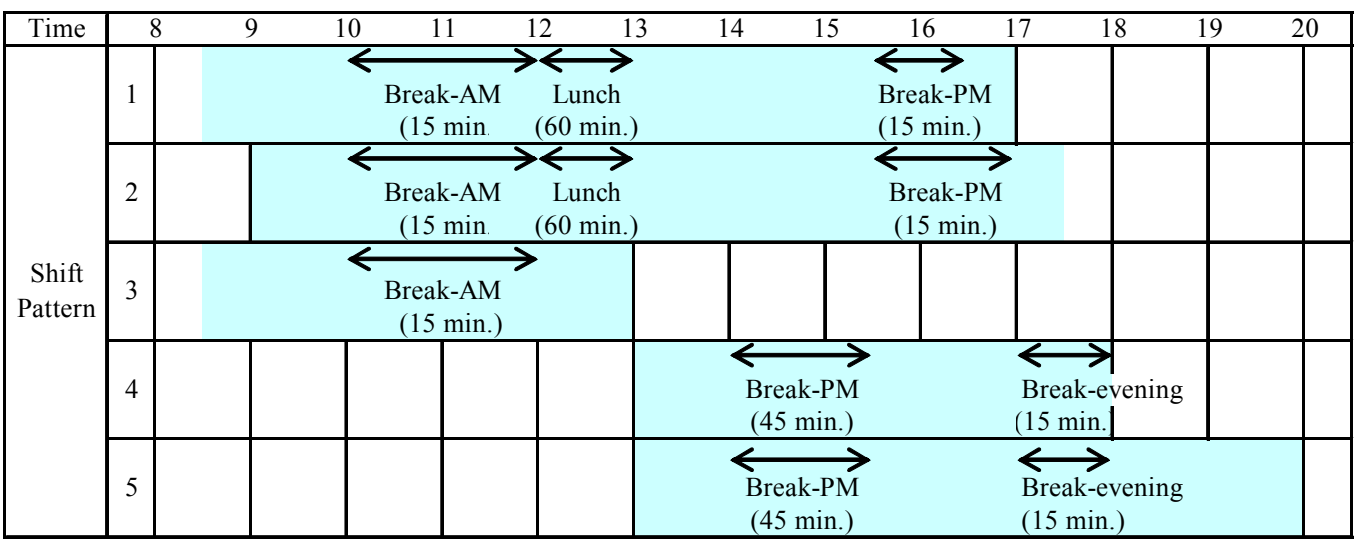

Figure 3: Shift Patterns of Agents

Table 1: Process Times of Agents (in seconds)

\begin{tabular}{|l|r|r|r|r|r|r|}
\hline \multirow{2}{*}{ Agent Skill } & \multicolumn{3}{|c|}{ Talk Time } & \multicolumn{3}{|c|}{ After-call Work Time } \\
\cline { 2 - 7 } & Min. & Mode & Max. & Min. & Mode & Max. \\
\hline Low (A) & 30 & 240 & 600 & 0 & 480 & 900 \\
\hline Middle (B) & 30 & 180 & 600 & 0 & 200 & 900 \\
\hline High (C) & 30 & 150 & 600 & 0 & 160 & 900 \\
\hline
\end{tabular}

ers are connected to agents within one minute, the service level is simply denoted as $95 / 60$. The service level target must be set before performing the proposed procedures. In the procedure, constrained optimization is performed because the service level target is a constraint. The procedures to seek the optimal solution can be itemized as follows:

1. Obtain an initial feasible solution via integer linear programming, as described in section 3.2.

2. Obtain a better feasible solution by modifying recesses for each agent by applying the proposed method as described in section 3.3.

3. Obtain an optimal solution in terms of the minimum number of selected agents by performing simulation together with constrained direct-search methods, as described in section 3.4. The recesses for each agent should be modified before performing simulation.

4. Repeat Step 3 for all designated agents in turn.
5. Compare performance including the total daily personnel expenses of eligible solutions on all possible scenarios.

\subsection{Integer Programming Model}

The problem is to determine the optimal number of each type of agents necessary to process customer calls. The overall objective is to minimize the total daily personnel expenses where the hourly wages are set based on the degree of the skill of the agent. The constraints can be formulated as the expected number of calls in each time interval, say, thirty minutes or one hour. An integer linear programming problem is a linear program in which all of the variables are restricted to integer values (Ignizio and Cavalier 1994). Paid and unpaid breaks are taken into consideration in the problem formulation. The service level constraints, however, are not considered, because they can not be estimated in advance. By using a matrix notation, an integer programming problem may be written as follows:

Find $\boldsymbol{x}$ so as to minimize $c x$ subject to:

Table 2: Parameters on Agents

\begin{tabular}{|c|c|c|c|c|c|c|c|c|c|}
\hline Shift Pattern & \multicolumn{2}{|c|}{1} & 2 & \multicolumn{2}{|c|}{3} & \multicolumn{2}{|c|}{4} & \multicolumn{2}{c|}{5} \\
\hline Agent Skill & $\mathrm{A}$ & $\mathrm{B}$ & $\mathrm{C}$ & $\mathrm{A}$ & $\mathrm{B}$ & $\mathrm{A}$ & $\mathrm{B}$ & $\mathrm{A}$ & $\mathrm{B}$ \\
\hline Number of Agents & $x_{1 \mathrm{~A}}$ & $x_{1 \mathrm{~B}}$ & $x_{2 \mathrm{C}}$ & $x_{3 \mathrm{~A}}$ & $x_{3 \mathrm{~B}}$ & $x_{4 \mathrm{~A}}$ & $x_{4 \mathrm{~B}}$ & $x_{5 \mathrm{~A}}$ & $x_{5 \mathrm{~B}}$ \\
\hline Contracted Labor Time (min.) & 510 & 510 & 510 & 270 & 270 & 360 & 360 & 420 & 420 \\
\hline Paid Break (min.) & 25 & 25 & 25 & 15 & 15 & 15 & 15 & 15 & 15 \\
\hline Unpaid Break (min.) & 60 & 60 & 60 & 0 & 0 & 45 & 45 & 45 & 45 \\
\hline Break Time per 30 Minutes (min.) & 5 & 5 & 5 & 1.67 & 1.67 & 5 & 5 & 4.29 & 4.29 \\
\hline Calls Processed per 30 Minutes (min.) & 2 & 2.31 & 2.44 & 2.27 & 2.62 & 2 & 2.31 & 2.06 & 2.38 \\
\hline Daily Wages (\$) & 135 & 138.75 & 142.50 & 74.25 & 76.50 & 94.50 & 97.12 & 112.50 & 115.62 \\
\hline
\end{tabular}


$A x \geq b$

$\boldsymbol{x} \geq \mathbf{0}, \boldsymbol{x}$ integer-valued,

where
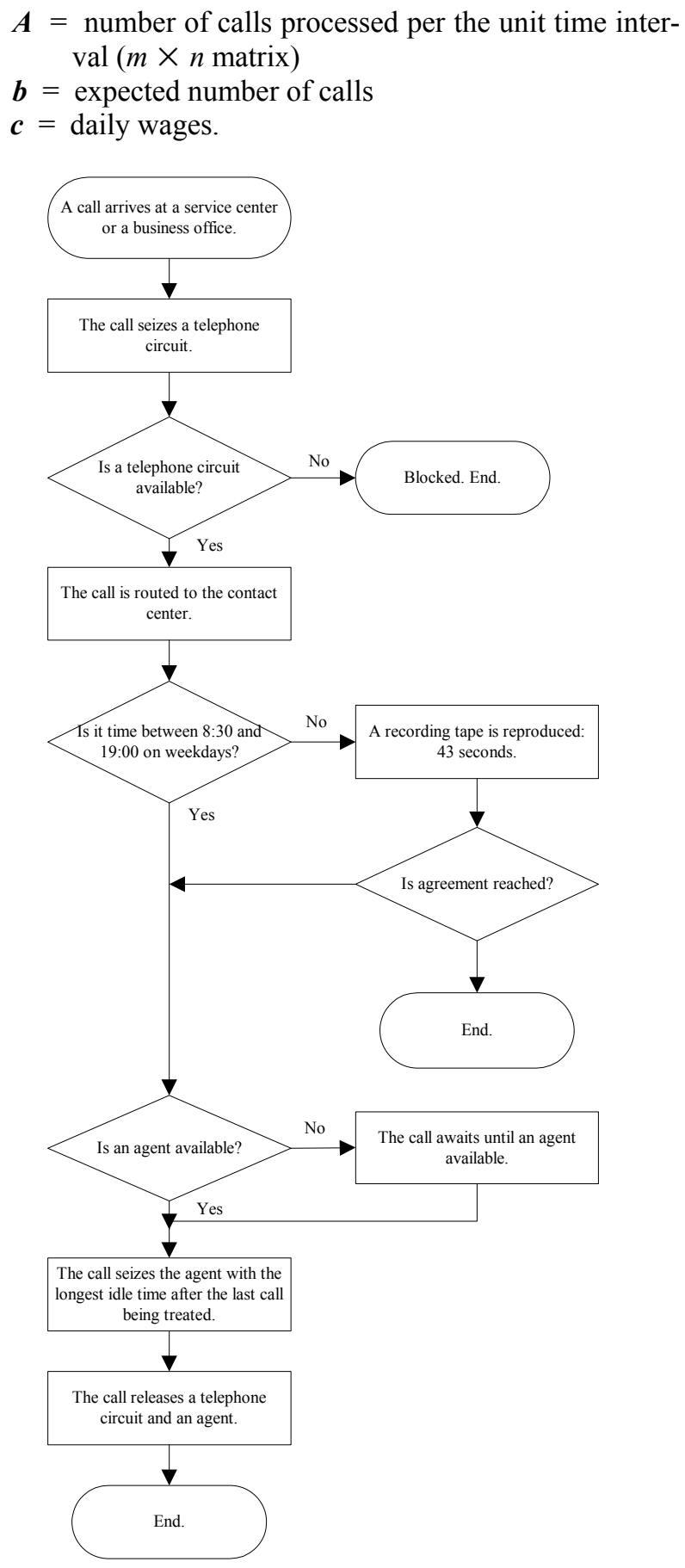

Figure 4: Flow of Calls

\subsection{The System Adjusting to Planned Recesses of Agents}

A set of numbers of agents were obtained via either integer programming or direct-search methods. The specific system was designed and developed to adjust the planned recesses of agents to meet the frequency of expected customer calls in each time interval. This system was developed by utilizing Excel VBA interface to specify a series of system parameters more easily. Once both call arrival rates and the number of agents are inputted into the designated dialog boxes, the resultant agent schedule can be obtained immediately. The dialog boxes for inputting these parameters are shown in Figure 5. As an example, the expected abilities of both the pre and post adjustment of the recesses of the agents are compared with the expected number of calls, as shown in Figure 6. It has been observed that the expected ability after adjustment fit with the expected number of calls than before adjusting.

\subsection{Constrained Direct-Search Methods}

Because the specified service level target should be taken into consideration through the process of optimization, the constrained direct-search methods may be applied together with statistical tests by using a simulation interactively. A variety of numerical techniques for extremizing both onedimensional and multidimensional objective functions can be applied (Gottfried and Weisman 1973). For example, the Fibonacci search method may be applied to the former, and the pattern search method may be applied to the latter (Takakuwa 1989; Takakuwa 1990).

Suppose that two alternatives are to be compared on a performance. In this case the two alternatives satisfy the constraints and statistical tests such as Paired- $t$ Test and Two-Sample- $t$ Test would be required to show which is the best alternative.

\section{APPLICATION}

In this section, the proposed procedure is applied to an actual case. The expected number of call arrival rates at the normal season is summarized in Table 3. After eliminating redundant constraints, the resultant integer programming model is shown as follows:

$$
\begin{aligned}
& \text { Find } x_{i j}(i=1,2, \ldots, 5, j=\mathrm{A}, \mathrm{B}, \mathrm{C}) \text { so as to } \\
& \text { minimize } \\
& 135.00 x_{1 \mathrm{~A}}+138.75 x_{1 \mathrm{~B}}+142.50 x_{2 \mathrm{C}}+74.25 x_{3 \mathrm{~A}}+ \\
& 76.50 x_{3 \mathrm{~B}}+94.50 x_{4 \mathrm{~A}}+97.12 x_{4 \mathrm{~B}}+112.50 x_{5 \mathrm{~A}}+115.62 x_{5 \mathrm{~B}} \\
& \text { subject to } \\
& 2 x_{1 \mathrm{~A}}+2.31 x_{1 \mathrm{~B}}+2.27 x_{3 \mathrm{~A}}+2.62 x_{3 \mathrm{~B}} \geq 69 \\
& 2 x_{1 \mathrm{~A}}+2.31 x_{1 \mathrm{~B}}+2.44 x_{2 \mathrm{C}}+2.27 x_{3 \mathrm{~A}}+2.62 x_{3 \mathrm{~B}} \geq 258.5
\end{aligned}
$$




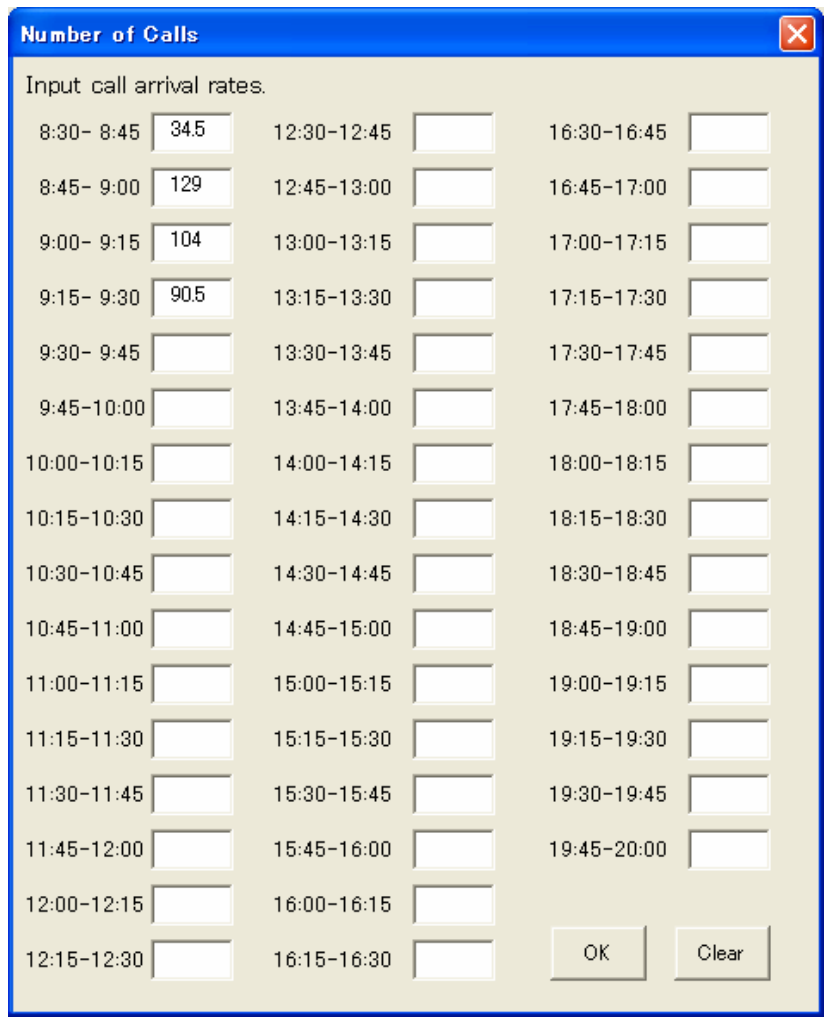

(a) Inputting Call Arrival Rates

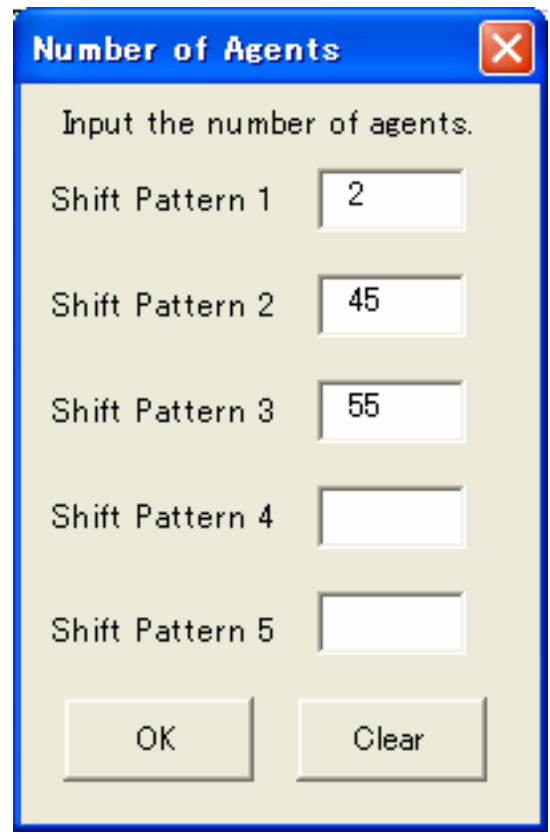

(b) Inputting the Number of Agents

Figure 5: System for Adjusting Planned Recesses of Agents

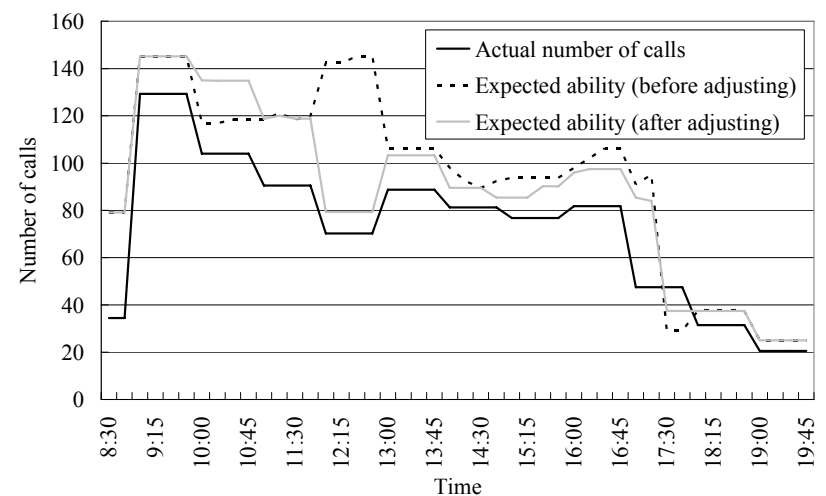

Figure 6: Expected Ability before and after Adjusting Recesses

Table 3: Call Arrival Rates

\begin{tabular}{|c|r|r|r|r|r|r|r|}
\hline \multirow{2}{*}{ Time } & \multicolumn{2}{|r|}{ Service Centers } & \multicolumn{3}{|c|}{ Business Offices } & \multirow{2}{*}{ Total } \\
\cline { 2 - 7 } & SC1 & SC2 & $\ldots$ & BO1 1 & BO2 & $\ldots$ & \\
\hline $8: 30-9: 00$ & 1 & 0 & $\ldots$ & 11 & 12 & $\ldots$ & 69 \\
\hline $9: 00-10: 00$ & 5 & 3 & $\ldots$ & 84 & 88 & $\ldots$ & 517 \\
\hline $10: 00-11: 00$ & 4 & 2 & $\ldots$ & 68 & 71 & $\ldots$ & 416 \\
\hline $11: 00-12: 00$ & 3 & 2 & $\ldots$ & 59 & 61 & $\ldots$ & 362 \\
\hline $12: 00-13: 00$ & 3 & 1 & $\ldots$ & 46 & 48 & $\ldots$ & 281 \\
\hline $13: 00-14: 00$ & 3 & 2 & $\ldots$ & 58 & 60 & $\ldots$ & 355 \\
\hline $14: 00-15: 00$ & 3 & 2 & $\ldots$ & 52 & 55 & $\ldots$ & 325 \\
\hline $15: 00-16: 00$ & 3 & 2 & $\ldots$ & 50 & 52 & $\ldots$ & 307 \\
\hline $16: 00-17: 00$ & 3 & 2 & $\ldots$ & 53 & 55 & $\ldots$ & 327 \\
\hline $17: 00-18: 00$ & 2 & 1 & $\ldots$ & 31 & 32 & $\ldots$ & 190 \\
\hline $18: 00-19: 00$ & 1 & 1 & $\ldots$ & 20 & 21 & $\ldots$ & 128 \\
\hline $19: 00-20: 00$ & 1 & 0 & $\ldots$ & 13 & 14 & $\ldots$ & 82 \\
\hline Total & 32 & 18 & $\ldots$ & 545 & 569 & $\ldots$ & 3357 \\
\hline
\end{tabular}

$2 x_{1 \mathrm{~A}}+2.31 x_{1 \mathrm{~B}}+2.44 x_{2 \mathrm{C}}+2 x_{4 \mathrm{~A}}+2.31 x_{4 \mathrm{~B}}+2.06 x_{5 \mathrm{~A}}+$ $2.38 x_{5 \mathrm{~B}} \geq 177.5$

$2.44 x_{2 \mathrm{C}}+2 x_{4 \mathrm{~A}}+2.31 x_{4 \mathrm{~B}}+2.06 x_{5 \mathrm{~A}}+2.38 x_{5 \mathrm{~B}} \geq 95$

$2 x_{4 \mathrm{~A}}+2.31 x_{4 \mathrm{~B}}+2.06 x_{5 \mathrm{~A}}+2.38 x_{5 \mathrm{~B}} \geq 63$

$2.06 x_{5 \mathrm{~A}}+2.38 x_{5 \mathrm{~B}} \geq 41$

$x_{i j} \geq 0 \quad(i=1,2, \ldots, 5, j=\mathrm{A}, \mathrm{B}, \mathrm{C})$, integer-valued,

where $i$ represents a shift pattern, and $j$ represents the degree of skill. The resultant solution is obtained as an initial feasible solution:

Shift pattern 1, Agent skill B: 2 (persons)

Shift pattern 2, Agent skill C: 45 (persons)

Shift pattern 3, Agent skill B: 55 (persons)

Shift pattern 4, Agent skill B: 9 (persons)

Shift pattern 5, Agent skill B: 18 (persons).

The total daily personnel expenses is expected to be $13,852.74$ (\$).

The assignment of the agents to the location of seats was shown in Figure 1. Starting with the initial feasible solution (Scenario 1) obtained at Step 1 of the procedure mentioned in section 3.1, three scenarios (Scenarios 2, 3, 


\section{Takakuwa and Okada}

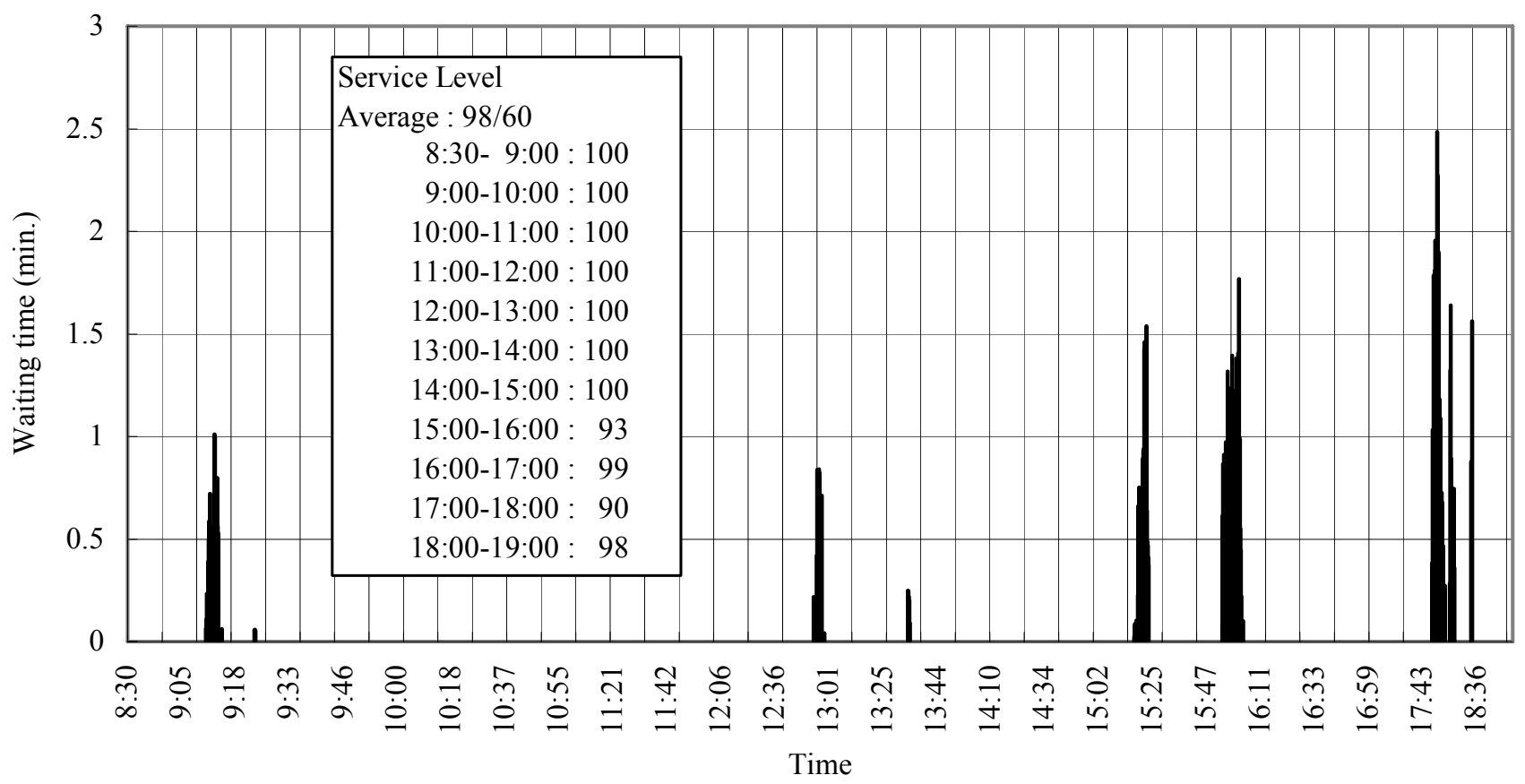

Figure 7: Service Level obtained by Performing Simulation

and 4) were obtained by applying the proposed procedure. The occurrence of waiting is illustrated for Scenario 1 in Figure 7, and the service level is $98 / 60$ in this case. The numbers of agents for each scenario and the associated total daily personnel expenses are summarized in Table 4. In addition, a 95\% confidence interval on the service level for each scenario is shown in Figure 8. A final decision might be made, by reviewing the results of multiple scenarios. Scenario 3, for example, could be selected because of the minimum daily personnel expenses, whereas Scenario 1 might be selected because of the highest service level among all eligible scenarios.

\section{CONCLUSIONS}

A simulation model of an inbound call center of a city-gas company was constructed and used to examine the service level target. A special-purpose system was designed and produced to modify the planned recesses of the agents to meet the frequency of customer calls.

A stepwise procedure of operations planning was proposed to minimize the total daily personnel expenses, by performing a simulation together with integer programming and the constrained direct-search methods. The initial solution was obtained by solving the integer programming problem, and the service level was evaluated by performing the simulation. It is found that the proposed procedure is applicable and effective to the real situation.
Table 4: Summary for Each Scenario

\begin{tabular}{|c|r|r|r|r|}
\hline Agent Type & Scenario 1 & Scenario 2 & Scenario 3 & Scenario 4 \\
\hline $\begin{array}{c}\text { Shift Pattern 1 } \\
\text { Agent Skill B }\end{array}$ & 2 & 2 & 2 & 2 \\
\hline $\begin{array}{c}\text { Shift Pattern 2 } \\
\text { Agent Skill C }\end{array}$ & 45 & 41 & 45 & 45 \\
\hline $\begin{array}{c}\text { Shift Pattern 3 } \\
\text { Agent Skill B }\end{array}$ & 55 & 55 & 50 & 52 \\
\hline $\begin{array}{c}\text { Shift Pattern 4 } \\
\text { Agent Skill B }\end{array}$ & 9 & 9 & 4 & 9 \\
\hline $\begin{array}{c}\text { Shift Pattern 5 } \\
\text { Agent Skill B }\end{array}$ & 18 & 18 & 18 & 14 \\
\hline $\begin{array}{c}\text { Total Number } \\
\text { of Agents }\end{array}$ & 129 & 125 & 119 & 122 \\
\hline Total Expenses (\$) & 13852.7 & 13282.7 & 12984.6 & 13160.8 \\
\hline
\end{tabular}

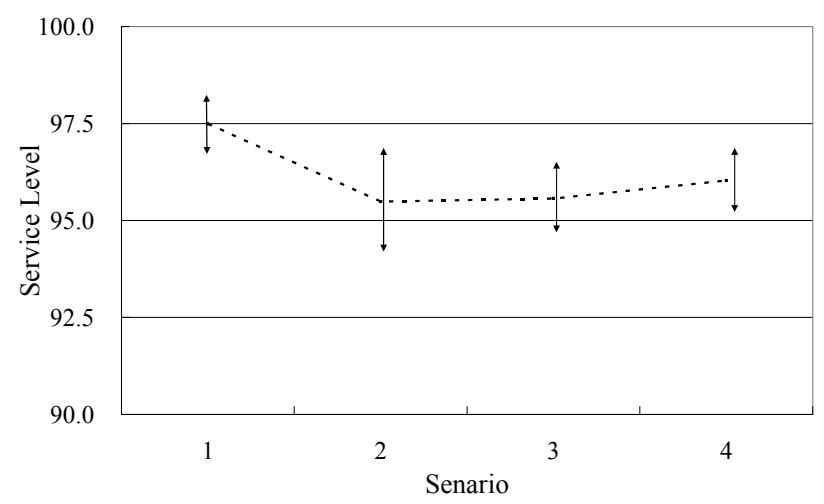

Figure 8: 95\% Confidence Interval on the Service Level 


\section{ACKNOWLEDGMENTS}

The authors wish to express sincere gratitude for Toho Gas Co., Ltd. for the acknowledgment of this research. Special thanks should be expressed to Mr. Kiyoshi Kato of General Manager of Customer Service Promotion Department, Mr. Seishi Okuyama of General Manager of Customer Center, Mr. Yasuhiko Hasegawa of Assistant Manager of Customer Center, Ms. Yumi Hasegawa, and Mr. Noritaka Ban of Toho Gas Co., Ltd.

\section{REFERENCES}

Anton, J., V. Bapat, and B. Hall. 1999. Call Center Performance Enhancement Using Simulation and Modeling. West Lafayette, Indiana: Purdue University Press.

Gottfried, B. S., and J. Weisman. 1973. Introduction to Optimization Theory. Englewood Cliffs, New Jersey: Prentice-Hall, Inc.

Henderson, S. G., and A. J. Mason. 1998. Rostering by iterating integer programming and simulation. In Proceedings of the 1998 Winter Simulation Conference, ed. D.J. Medeiros, E.F. Watson, J. S. Carson and M. S. Manivannan, 677-683. Institute of Electrical and Electronics Engineers, Piscataway, New Jersey: Available online via http://www.informsC. . org/W.sc98papers / 090. PDF.

Ignizio, J. P., and T. M. Cavalier. 1994. Linear Programming. Englewood Cliffs, New Jersey: Prentice-Hall, Inc.

Kelton, W. D., R. P. Sadowski, and D. T. Sturrock. 2004. Simulation with ARENA. $3^{\text {rd }}$ ed. New York: McGrawHill.

Klungle, R. 1999. Simulation of a claims call center: a success and a failure. In Proceedings of the 1999 Winter Simulation Conference, ed. P. A. Farrington, H. B. Nembhard, D. T. Sturrock and G. W. Evans, 16481653. Piscataway, New Jersey: Institute of Electrical and Electronics Engineers, Available online via http: / /www. informs -

C. . org/wsc99papers/238. PDF.

Koole, G., A. Pot, and J. Talim. 2003. Routing heuristics for multi-skill call centers. In Proceedings of the 2003 Winter Simulation Conference, ed. S. Chick, P. J. Sanchez, D. Ferrin, and D. J. Morrice, Institute of Electrical and Electronics Engineers, 1813-1816. Piscataway, New Jersey: Available online via http: / / www. informsCs.org/wsc03papers/232.pdf.

Mazzuchi, T. A., and R. B. Wallace. 2004. Analyzing skillbased routing call centers using discrete-event simulation and design experiment. In Proceedings of the 2004 Winter Simulation Conference, ed. R.G. Ingalls, M. D. Rossetti, J. S. Smith and B. A. Peters, 1812-
1820. Institute of Electrical and Electronics Engineers, Piscataway, New Jersey: Available online via http: / / www. informs-

C. . org/wsc04papers / 240 . pdf.

Mehrotra, V., and J. Fama. 2003. Call center simulation modeling: methods, challenges, and opportunities. In Proceedings of the 2003 Winter Simulation Conference, ed. S. Chick, P. J. Sanchez, D. Ferrin, and D. J. Morrice, Institute of Electrical and Electronics Engineers, 135-143. Piscataway, New Jersey: Available online via http://www. informs C. .org/wsc03papers/016.pdf.

Pichitlamken, J., A. Deslauriers, P. L'Ecuyer, and A. N. Avramidis. 2003. Modelling and simulation of a telephone call center. In Proceedings of the 2003 Winter Simulation Conference, ed. S. Chick, P. J. Sanchez, D. Ferrin, and D. J. Morrice, Institute of Electrical and Electronics Engineers, 1805-1812. Piscataway, New Jersey: Available online via http: / / www. informsC. . org/wsc03papers/231.pdf.

Saltzman, R., and V. Mehrotra. 2004. A manager-friendly platform for simulation modeling and analysis of call center queueing systems. In Proceedings of the 2004 Winter Simulation Conference, ed. R.G. Ingalls, M. D. Rossetti, J. S. Smith and B. A. Peters, 466-473. Institute of Electrical and Electronics Engineers, Piscataway, New Jersey: Available online via http: / / www. informs Cs . org/wsc04papers / 056 . pdf.

Takakuwa, S. 1989. Module modeling and economic optimization for large-scale AS/RS. In Proceedings of the 1989 Winter Simulation Conference, ed. E. A. MacNair, K. J. Musselman, P. Heidelberger, 795-801. Piscataway, New Jersey: Institute of Electrical and Electronics Engineers.

Takakuwa, S. 1990. Multiobjective optimization and analysis of picking/conveyance systems. In Proceedings of the 1990 Winter Simulation Conference, ed. O. Balci, R. P. Sadowski, R. E. Nance, 707-713. Piscataway, New Jersey: Institute of Electrical and Electronics Engineers.

Tanir, O., and R. J. Booth. 1999. Call center simulation in Bell Canada. In Proceedings of the 1999 Winter Simulation Conference, ed. P. A. Farrington, H. B. Nembhard, D. T. Sturrock and G. W. Evans, 1640-1647. Piscataway, New Jersey: Institute of Electrical and Electronics Engineers, Available online via http: / / www. informs Cs.org/wsc99papers/237. PDF. 


\section{AUTHOR BIOGRAPHIES}

SOEMON TAKAKUWA is a Professor and Chair in the Graduate School of Economics and Business Administration at Nagoya University in Japan. He received his B. Sc. and M. Sc. degrees in industrial engineering from Nagoya Institute of Technology in 1975 and from Tokyo Institute of Technology in 1977 respectively. His Ph.D. is in industrial engineering from The Pennsylvania State University. He holds Doctorate of Economics from Nagoya University. His research interests include optimization of manufacturing and logistics systems, management information system and simulation analysis on these systems including hospitals. He has prepared the Japanese editions of both Introduction to simulation using SIMAN and Simulation with ARENA. He has been serving concurrently as the senior staff of Department of Hospital Management Strategy and Planning at Nagoya University Hospital. His e-mail address is takakuwalsoec.nagoya-u.ac.jp.

TAKAKO OKADA received her B. Sc. and M. Sc. degrees in Economics from Nagoya University in 2003 and 2005, respectively. After that, she works for Matsushita Electric Industrial Co., Ltd. Her e-mail address is gateaux_fraise15@ybb.ne.jp. 